\title{
АНАЛИЗ РЕАЛИЗУЕМЫХ ГОСУДАРСТВЕННЫХ МЕР ПОДДЕРЖКИ НЕКОММЕРЧЕСКИХ ОРГАНИЗАЦИЙ В МУРМАНСКОЙ ОБЛАСТИ
}

\author{
(C) 2021 Пашинцева Виктория Сергеевна \\ студент-магистр \\ Университет ИТМО, Россия, Санкт-Петербург \\ E-mail: victoria.polukhina@mail.ru
}

Обеспечение устойчивого социально экономического развития страны во многом зависит от взаимодействия некоммерческих организаций, социального бизнеса и органов государственной власти, местного самоуправления в решении важнейших социальных задач. Именно поэтому научная статья посвящена проведению исследовательского анализа характеристики и особенностей мероприятий государственной поддержки некоммерческих организаций на региональном уровне (на примере Мурманской области). В рамках статьи проанализирована федеральная и региональная нормативно-правовая база в части форм предоставления государственной поддержки некоммерческим организациям. В заключении статьи автором установлено, что благодаря мерам государственной поддержки некоммерческих организаций в Мурманской области, данные субъекты хозяйствования мотивированы на решение социальных проблем населения региона путем повышения качества и разнообразия услуг в социальной сфере. По этой причине перспективами участия регионального правительства в управлении негосударственным сектором является расширение мероприятий государственной поддержки, в особенности предоставления финансовой помощи в рамках закупочной деятельности, налоговых послаблений и информационной поддержки некоммерческих организаций.

Ключевые слова: некоммерческие организации, государственная поддержка, субсидии, социальная деятельность.

В последнее время российское государство проводит вполне отчетливую политику поддержки некоммерческих организаций (далее НКО), при которой органы государственной власти и НКО сотрудничают в целях реализации значимых проектов как равноправные партнеры. Об этом свидетельствуют принимаемые на уровне государства решения.

В послании Президента Российской Федерации Федеральному Собранию в 2014 года отмечена важность исключения дискриминации негосударственного сектора в социальной сфере и барьеров для него, обеспечения равного доступа к финансовым средствам [1]. Посланием 2015 года предусмотрены запуск специальной программы президентских грантов для поддержки НКО, работающих в малых городах и селах, введение правового статуса «НКО - исполнитель общественно полезных услуг» и установление для них ряда льгот и преференций, а также поэтапное направление некоммерческим организациям до $10 \%$ средств региональных и муниципальных социальных программ [2]. В рамках послания 2016 года внимание регио- нальных и муниципальных властей акцентировано на максимальном привлечении некоммерческих организаций к исполнению социальных услуг [3].

Как следствие, системная и долгосрочная основа партнерства государства и НКО закреплена в Основных направлениях деятельности Правительства Российской Федерации на период до 2024 года [4], где работа с НКО-сектором и привлечение негосударственных организаций в сферу оказания социальных услуг выделено в отдельное направление.

Основным документом, регламентирующим деятельность некоммерческих организаций, является Федеральный закон от 12.01.1996 № 7-Ф3 «О некоммерческих организациях», в котором закреплены основные понятия, описываются основополагающие принципы работы некоммерческих организаций и виды деятельности социально ориентированных некоммерческих организаций [5]. Также в вышеуказанном федеральном законе обозначены государственные меры информационной, имущественной, инфраструктурной и финансовой поддержки НКО, 
способы и правила взаимодействия органов государственной власти и некоммерческих организаций.

Работа Правительства Мурманской области в части поддержки деятельности некоммерческих организаций, в том числе социально ориентированных некоммерческих организаций, и социального бизнеса также является одним из долгосрочных приоритетов региональной политики.

На территории региона деятельность по привлечению некоммерческих организаций к оказанию услуг в социальной сфере осуществляется в рамках мероприятий, предусмотренных:

- Планом мероприятий («дорожной карты») по содействию развитию конкуренции в Мурманской области до 2022 года;

- Комплексным планом мероприятий Мурманской области по обеспечению поэтапного доступа негосударственных организаций к предоставлению услуг в социальной сфере, финансируемых из бюджетных источников (утв. распоряжением Правительства Мурманской области;

- государственных программах Мурманской области

Правительство Мурманской области предус- матривает меры, направленные на увеличение поддержки СО НКО.

Размер финансовой поддержки в разрезе механизмов предоставления финансовых средств НКО за 2018-2020 гг. представлен на рисунке 1 [6].

Из рисунка 1 видно, что объем государственной финансовой поддержки, представленной НКО из бюджета Мурманской области, в 2020 году увеличился на 47\% по отношению к 2018 году и составил 98,4 млн. рублей. При этом больше всего средств на финансовую поддержку НКО предоставляется в виде прямой целевой субсидии (43\% от общего объема средств в 2020 году). Стоит отметить, что на рисунке 1 не представлена финансовая поддержка СО НКО в виде закупки услуг по Федеральному закону от 05.04.2013 № 44-Ф3 «О контрактной системе в сфере закупок товаров, работ, услуг для обеспечения государственных и муниципальных нужд», так как она не предоставлялась на всем исследуемом периоде (НКО не принимали участие в закупках, либо не являлись победителями).

Объем государственной финансовой поддержки, представленной на конкурсной основе,

В виде компенсации за оказанные СОНКО услуги по Ф3-442 от 28 декабря 2013 г. «Об основах социального обслуживания граждан в Российской Федерации» (тыс. руб.)

В виде субсидии, предоставленной СОНКО на конкурсной основе (тыс. руб.)

В виде прямой целевой субсидии, предоставленной СОНКО (тыс. руб.)

Объем государственной финансовой поддержки, предоставленной СОНКО из бюджета Мурманской области (тыс. руб.)

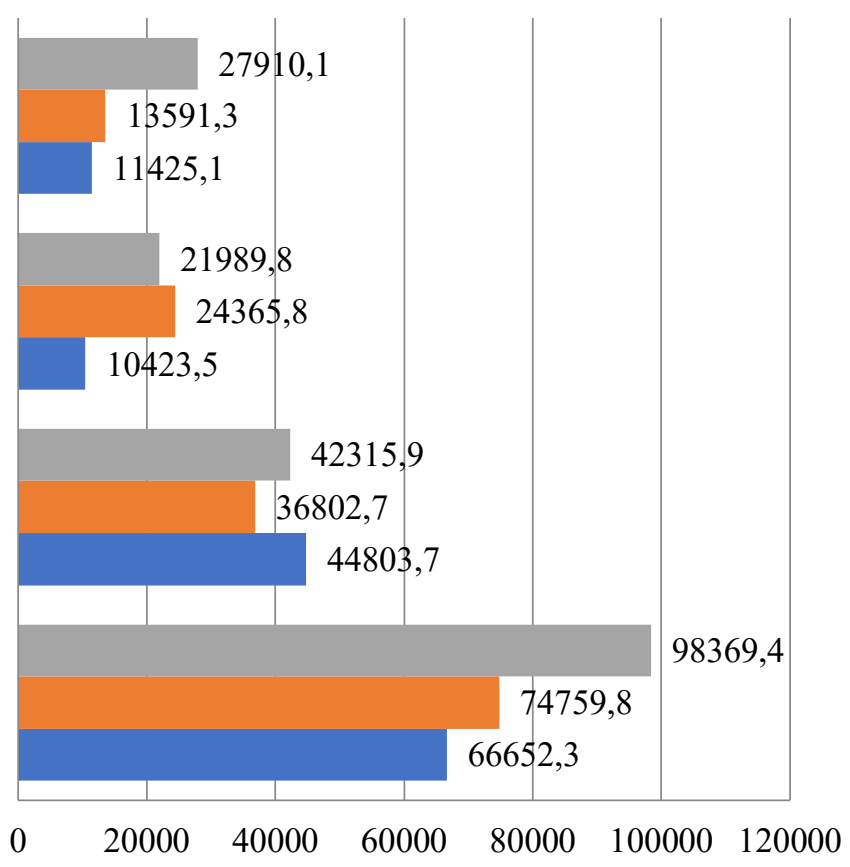

$\square 2020 \square 2019 \square 2018$

Рис. 1. Размер финансовой поддержки СО НКо органами исполнительной власти Мурманской области в 2018-2020 гг. (тыс. руб.)

Финансовая поддержка СО НКО предоставлялась в сферах образования, социального обслуживания, культуры, физической культуры и спорта, здравоохранения и молодежной политики. 
в 2020 году уменьшился на 10\% по сравнению с предыдущим годом. Прежде всего, это связано с отменой значительного числа мероприятий в сфере культуры, физической культуры и спорта в связи с введением ограничительных мер, принятых в целях недопущения распространения коронавирусной инфекции (соглашения о предоставлении средств расторгались в течение года в связи с отменой ранее запланированных мероприятий).

Объемы компенсации затрат за оказанные некоммерческими организациями социальные услуги в рамках Федерального закона от 28.12.2013 № 442-Ф3 «Об основах социального обслуживания граждан в Российской Федерации» увеличились в 2 раза (на 105\%) в 2020 году за счет возросшей нагрузки в сфере социальных услуг из-за ограничительных мер, принятых в целях недопущения распространения коронавирусной инфекции (социальное обслуживание на дому людей, возрастом 65 лет и старше, инвалидов, людей с хроническими заболеваниями, находящихся на самоизоляции).

Также на увеличение компенсации затрат влияет и рост числа СО НКО в реестре поставщиков социальных услуг [7]. В 2020 году доля негосударственных организаций в реестре увеличилась на 1\% по сравнению с 2019 годом и достигла 53,2\%, это 25 организации из 47 (в 2019 г. - 52,2\%, в 2018 г. - 45\%), и это учитывая тот факт, что 3 негосударственных организации вышли из реестра в связи с ликвидаций организации.

Оказание НКО имущественной поддержки осуществляется посредством передачи во владение или в пользование НКО государственного имущества (передача в аренду, в том числе, по льготным ставкам арендной платы), установления льготных ставок арендной платы за пользование земельными участками (предоставление через специализированную организацию). В Мурманской области сформирован перечень государственного имущества, предназначенного для предоставления в безвозмездное пользование социально ориентированным НКО (утвержден постановлением Правительства Мурманской области от 23.11.2011 № 579-ПП) [8].

В 2020 году данная поддержка оказана на безвозмездной основе 22 НКО без проведения конкурса - общая площадь составила 88,01 тыс. кв. м. [6].

Стоит отметить, что с целью имущественной поддержки НКО в рамках ограничительных мер, связанных с распространением коронавирусной инфекции на территории Мурманской области, организациям предоставляется освобождение от уплаты арендных платежей по договорам аренды имущества, составляющего казну Мурманской области, за апрель-июнь 2020 года. Также предоставляется отсрочка оплаты аренды иного государственного недвижимого имущества Мурманской области на весь период действия ограничительных мер путем заключения дополнительного соглашения, устанавливающего отсрочку оплаты арендной платы, предусмотренной в 2020 году, и ее уплату равными частями в 2021 году.

В 2019-2021 гг. реализовывается образовательная поддержка представителей $\mathrm{HKO} \mathrm{Pe}-$ сурсным центром по поддержке социально ориентированных некоммерческих организаций. Целью деятельности данного центра является содействие развитию некоммерческого сектора экономики Мурманской области с учетом региональной компоненты, распространение новых технологий и лучших практик работы в социальной сфере, оказание помощи НКО в получении грантов от благотворителей, включая Фонд Президентских грантов.

Ресурсным центром СО НКО в 2020 году были проведены 8 вебинаров (по таким тематикам, как работа НКО в интернет-среде и их взаимодействие со СМИ; финансовый менеджмент социально ориентированных НКО (в т.ч. привлечение финансирования); правовые аспекты деятельности НКО и их отчетность) и образовательных мероприятий. При этом привлекались порядка 11 иногородних эксперта для проведения указанных обучающих мероприятий [6].

Виды налоговой поддержки в Мурманской области представлены в таблице 1. Стоит отметить, что в регионе не осуществляется представление налоговых льгот организациям, осуществляющим пожертвования НКО.

Консультативную поддержку на территории региона осуществляют две инфраструктурные единицы:

- Автономная некоммерческая организация социальных услуг и консультативной деятельности «Ресурсный центр некоммерческих организаций»;

- Ресурсный центр СО НКО (оператором которого является частное учреждение социального обслуживания «Социальный центр - SOS Мурманск», осуществляет проект в рамках суб- 


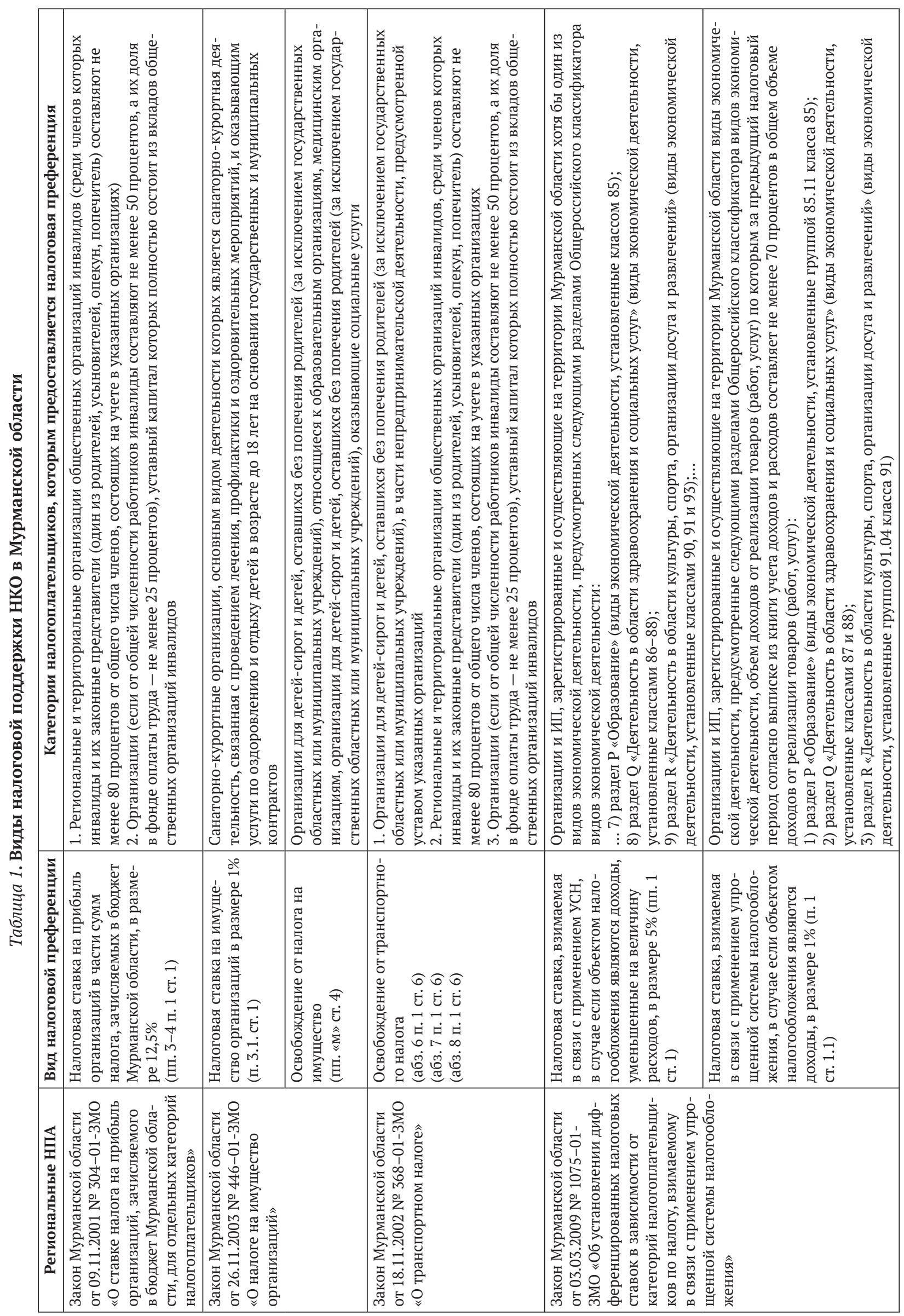


сидии на финансовое обеспечение деятельности Ресурсного центра СО НКО).

Кроме того, комплексное сопровождение НКО осуществляется сотрудниками органов государственной и муниципальной власти при вхождении организаций на рынок социальных услуг, включающее проведение индивидуальных консультаций и методических часов на площадках регионального Министерства труда и социального развития Мурманской области и подведомственных учреждений.

Таким образом, анализ государственных мер поддержки НКО в Мурманской области показал, что в регионе предоставляется финансовая, имущественная, консультационная поддержки, а также реализуется образовательная поддержка представителей НКО на базе Ресурсного центра социально ориентированных некоммерческих организаций и Министерства труда и социального развития Мурманской области. Также некоторым категориям НКО предоставляются льготы по уплате налогов и сборов в соответствии с региональным законодательством о налогах и сборах.

В целом отмечается, что в Мурманской области нет отдельных государственных программ по поддержке НКО. Мероприятия по предоставлению НКО бюджетных средств на оказание услуг в социальной сфере включены в различные отраслевые государственные программы. Осу- ществление закупок товаров, работ, услуг для обеспечения государственных и муниципальных нужд у социально ориентированных некоммерческих организаций в порядке, установленном законодательством Российской Федерации о контрактной системе в сфере закупок, на территории региона не проводится в связи с отсутствием заявок от НКО.

Подводя итоги научной работы, можно прийти к следующим заключениям:

1. Благодаря мерам государственной поддержки некоммерческих организаций в Мурманской области, данные субъекты хозяйствования мотивированы на решение социальных проблем населения региона путем повышения качества и разнообразия услуг в социальной сфере.

2. Перспективами участия Правительства Мурманской области в управлении негосударственным сектором является расширение мероприятий государственной поддержки, в особенности предоставления финансовой помощи в рамках закупочной деятельности, налоговых послаблений и информационной поддержки (размещение пресс-релизов о деятельности НКО на информационных ресурсах органов государственной власти, предоставление на безвозмездной основе эфирного времени на площадках региональных СМИ и т.п.).

\section{Библиографический список}

1. Послание Президента Российской Федерации Федеральному Собранию от 04.12.2014 «Послание Президента РФ Федеральному Собранию» [Электронный ресурс]. URL: http://kremlin.ru/events/president/news/47173 (дата обращения: 10.11.2021).

2. Послание Президента Российской Федерации Федеральному Собранию от 03.12.2015 «Послание Президента Российской Федерации» [Электронный ресурс]. URL: http://www.kremlin.ru/acts/bank/40542/page/3 (дата обращения: 10.11.2021).

3. Послание Президента Российской Федерации Федеральному Собранию от 01.12.2016 «Послание Президента Российской Федерации Федеральному Собранию» [Электронный ресурс]. URL: http:/kremlin.ru/events/ president/news/53379 (дата обращения: 10.11.2021).

4. «Основные направления деятельности Правительства Российской Федерации на период до 2024 года» (утв. Правительством РФ 29.09.2018) // СПС КонсультантПлюс.

5. Федеральный закон от 12.01.1996 № 7-Ф3 «О некоммерческих организациях» // СПС КонсультантПлюс.

6. Результаты мониторинга реализации мер по обеспечению поэтапного доступа негосударственных организаций, в том числе СО НКО, к бюджетным средствам на предоставление населению услуг в социальной сфере на территории Мурманской области в 2018-2020 гг. / сайт Министерства развития Арктики и экономики Мурманской области. URL: https://minec.gov-murman.ru/activities/sektor_byjet/75/analiticheskie-materialy/.

7. Реестр поставщиков социальных услуг / сайт Министерства труда и социального развития Мурманской области. URL: https://minsoc.gov-murman.ru/activities/social_services_fed_law/reestr_soc_service_providers/.

8. Постановление Правительства Мурманской области от 23.11.2011 № 579-ПП «Об утверждении перечня имущества, находящегося в государственной собственности Мурманской области, предназначенного для предоставления в безвозмездное пользование социально ориентированным некоммерческим организациям» [Электронный ресурс]. URL: https://property.gov-murman.ru/activities/perechni_imusch/per_sono/per_ sono.php 